p-ISSN. 2086-9029

e-ISSN. 2654-5675

Vol. 21 No. 1, HIm. 1-124, Juni 2019

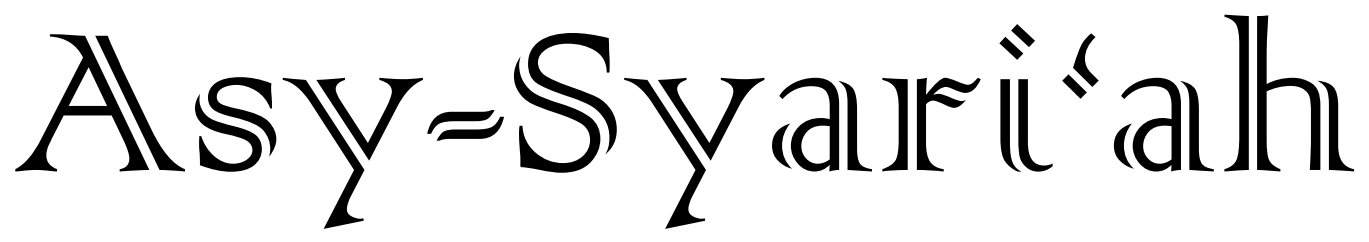

- Islam Nusantara's Perspective on Justice in Polygamy

Beni Ahmad Saebani

- Konstruksi Wakaf Secara Fikih

$(17-30)$ Jaenudin

- Pendekatan Maqashid Syari'ah dalam Praktik Pembiayaan di Koperasi Peternak Sapi Bandung Utara (KPSBU) Lembang Ade Iskandar Nasution

- Kaidah-Kaidah Islam Menjawab Permasalahan Sosial dan Ekonomi Umat

Neneng Hasanah dan Hamzah

- Inovasi Penyaluran Dana Zakat Pada Program Pemberdayaan di Lembaga Amil Zakat

Iw an Setiawan

- Perspektif Siyasah Dusturiyah atas Hak Politik Perempuan dalam Musrembang Kota Bogor

Erma Yulianis

- $\quad$ SBSN PBS, dan SUKRI sebagai Instrumen Pemerintah dalam

Pembiayaan APBN dan Investasi Masyarakat

Suteja Wira Dana Kusuma \& Nisa Dely Amalia

- Partisipasi Politik Kaum Perempuan berdasarkan Pandangan

Fatima Mernissi dan Yusuf Qardhawi

Gayatri Belina Jourdy

FACULTY OF SHARIA AND LAW

STATE ISLAMIC UNIVERSITY SUNAN GUNUNG DJATI BANDUNG-INDONESIA IN COLLABORATION WITH ASOSIASI SARJANA SYARIAH INDONESIA 


\section{Asy-Syari'ah}

\section{Volume 21, Number 1, 2019}

\section{EDITOR-IN-CHIEF}

Ine Fauzia

\section{EDITORIAL BOARD}

Sofyan al-Hakim, UIN Sunan Gunung Djati Bandung, Indonesia Deni Kamaludin Yusup, UIN Sunan Gunung Djati Bandung, Indonesia Meria Utama, Fakultas Hukum Univrsitas Sriwijaya, Indonesia Dewi Mayaningsih, UIN Sunan Gunung Djati Bandung, Indonesia Andrey Sujatmiko, Fakultas Hukum Universitas Trisakti, Jakarta, Indonesia Hetty Hassanah, Universitas Komputer Indonesia, Indonesia

\section{PEER-REVIEWERS}

Muhammad Irfan Helmy, IAIN Salatiga, Semarang, Indonesia Ahmad Ali Nurdin, UIN Sunan Gunung Djati Bandung Tajul Arifin, UIN Sunan Gunun Djati Bandung, Indonesia Mohamad Anton Athoillah, UIN Sunan Gunung Djati Bandung, Indonesia Mrs. Renny Supriyatni, Universitas Padjadjaran, Indonesia Ahmad Tholabi Karlie, UIN Syarif Hidayatullah Jakarta, Indonesia Ija Suntana, UIN Sunan Gunung Djati Bandung, Indonesia Zezen Zaenal Mutaqin, University of California, Los Angeles, United States Ahmad Fathonih, UIN Sunan Gunung Djati Bandung, Indonesia Rahman Syamsuddin, Universitas Islam Negeri Alauddin Makassar, Indonesia

\section{PROOFREADER/DESIGN COVER}

Nanang Sungkawa

\section{LAYOUT EDITOR}

Opik Rozikin

Asy-Syari' ah has been accredited based on the determination of Director General of Research and Development Strengthening, Ministry of Research, Technology and Higher Education of Republic of Indonesia, No. 14/E/KPT/2019 (valid until 2023). 


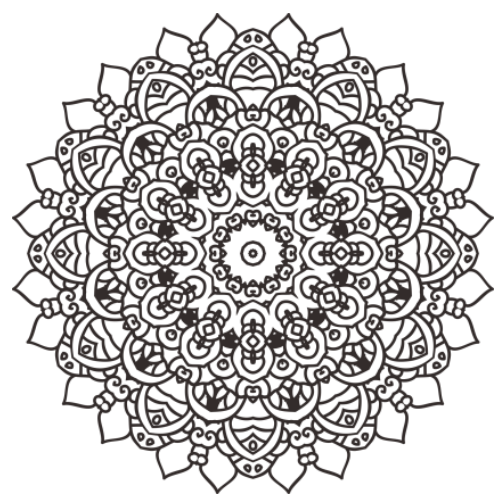

\title{
INOVASI PENYALURAN DANA ZAKAT PADA PROGRAM PEMBERDAYAAN DI LEMBAGA AMIL ZAKAT
}

\author{
Iwan Setiawan \\ Cahaya Insan Foundation \\ Email: iwan60555@gmail.com
}

\begin{abstract}
Zakat is intended to empowering the mustahik and improving their living standard. For this reason, the Islamic economic system through zakat is believed as one of solution to overcome social gap and inequalities. Qualitative descriptive research is used to reveal Zakat Law Number 23 of 2011 drafting as Law Number 38 of 1999 replacement; and al-Maqashid al-Shari'ah as analysis approach. The high poverty rate, the great potential of zakat, and the responsibility of the State promote the "productive zakat" in form of scholarships, venture capital, and other forms are inevitably, while distributing the fund to the eight asnaf as stated in Al Qur'an Surah At-Taubah verse 60.
\end{abstract}

Keywords: Legal politics, Zakat, Productive Zakat 


\begin{abstract}
Abstrak: Sistem ekonomi Islam melalui zakat merupakan solusi untuk menanggulangi kesenjangan sosial yang akan berakibat pada kecemburuan sosial, konflik sosial, bahkan sampai revolusi sosial. Pengelolaan zakat yang baik mendistribusikan dana zakat tidak bersifat konsumtif tetapi secara produktif baik dimensi ekonomi, pendidikan, bahkan sarana sosial lainnya sehingga mustahik mampu mengembangkan dana zakat yang diterima guna meningkatkan taraf kehidupannya. Penelitian deskriptif kualitatif digunakan untuk mengungkapkan kejadian atau fakta proses pembuatan undang-undang nomor 23 tahun 2011 sebagai perubahan dari undang-undang nomor 38 tahun 1999. Sedangkan untuk menganalisis digunakan pendekatan al-Maqashid al-Syari'ah. Angka kemiskinan yang tinggi dan potensi zakat yang besar serta tanggungjawab Negara dalam hal itu menjadikan pengelolaan zakat secara produktif seperti dalam bentuk beasiswa, permodalan, pemberian alat-alat produksi dan sebagainya adalah hal yang niscaya dengan tetap mendistribusikannya tidak keluar dari delapan asnaf yang tertuang dalam Al-quran surat At-Taubah ayat 60.
\end{abstract}

Kata Kunci: Politik hukum, Zakat, Zakat Produktif 


\section{Pendahuluan}

Harta merupakan sesuatu yang dicari oleh manusia. Dalam Al-Qur'an, harta disimbolkan dengan emas dan perak, sebagai perhiasan dunia dalam pandangan manusia yaitu sebagai sesuatu keindahan ${ }^{1}$. Manusia sebagai makhluk sosial yang dikaruniai naluri dan kebutuhan jasmani mendorong manusia untuk dinamis dengan cara berinovasi dalam mencari harta untuk memenuhi kebutuhannya. Kebutuhan yang mau tidak mau harus terpenuhi melahirkan interaksi diantara manusia. Namun manusia dengan sifat, watak, dan kemampuan yang berbeda secara alamiah menciptakan keadaan sosial yang berbeda. ${ }^{2}$

Keadaan perbedaan kuantitas kekayaan (miskin dan kaya) juga diakui didalam AlQur'an ${ }^{3}$. Keadaan sosial yang berbeda akibat dari perbedaan kemampuan, sifat, dan watak manusia kerapkali menjadi permasalahan. Pada masa dinasti Umar bin Khatab ada seseorang yang diadukan kepada Umar dengan dakwaan telah melakukan tindak pidana pencurian. Didalam Al-Qur'an hukuman bagi pencuri diancam dengan pidana potong tangan namun Umar sebagai khalifah tidak memutus demikian karena kejahatan yang dilakukan disebabkan karena saat itu ada dalam keadaan krisis, artinya keadaan ekonomi seseorang mempengaruhi tindakan seseorang. ${ }^{4}$

Islam sebagai agama yang rahmatan lil'alamiin tidak lepas dari keadaan alamiah manusia yang membutuhkan ekonomi. Sistem ekonomi fiskal Islam telah terbukti mengikis jarak yang memisahkan antara kaya dan miskin. Umar bin Abdul Azis meski masa pemerintahannya hanya berlangsung 22 bulan beliau berhasil mengelola zakat sehingga ketika utusannya pergi ke Afrika untuk mencari mustahik, utusannya tidak menjumpai mustahik. Pengelolaan zakat dibawah kepemimpinan Umar bin Abdul Azis mampu mengubah mustahik menjadi muzaki ${ }^{5}$. Hal itulah yang terus di upayakan di Indonesia dengan beragam regulasi yang ada mengenai pengelolaan zakat.

Negara Indonesia dengan penduduk masyoritas muslim mempunyai potensi besar dalam membangun kesejahteraan dengan instrument zakat. Berdasarkan hasil penelitian Baznas, potensi zakat di Indonesia mencapai 217 triliyun. Potensi yang besar itu tidak sebanding dengan dana zakat yang terkumpul hanya mencapai 1,729 triliyun. ${ }^{6}$ Upaya pemerintah dalam pengelolaan zakat terus berinovasi. Undang-undang nomor 23 tahun 2011 sebagai perubahan dari undang-undang nomor 38 tahun 1999 merupakan

1 Ali-Imran ayat 14 "dijadikan rasa indah dalam pandangan manusia cinta terhadap apa yang diinginkan berupa perempuan-perempuan, anak-anak, harta benda yang betumpuk, dalam bentuk emas dan perak, kuda pilihan, hewan ternak..."

${ }^{2}$ Anonim, Uang Kertas vs Dinar dan Dirham Islam (Bogor: Pustaka Izzah, 2011), hlm. 4.

3 Al-An'am ayat 165 "Dan Dialah yang menjadikan kamu penguasa-penguasa dibumi dan Dia meninggikan sebagian kamu atas sebagian yang lain beberapa derajat..."

${ }^{4}$ Rahmat Hakim, Hukum Pidana Islam (Bandung: Pustaka Setia, 2010), hlm. 86.

${ }^{5}$ Huda Nurul dan dkk, Zakat Perspektif Mikro-Makro Pendekatan Riset (Jakarta: Prenadamedia Group, 2015), hlm. 15 .

6 Jamal Ma'mur Asmani, Zakat Solusi Mengatasi Kemiskinan Umat (Yogyakarta: Aswaja, 2016), hlm. 40. 
ikhtiar pemerintah dalam mengikis kesenjangan sosial. Meski lahirnya undang-undang ini menuai kontroversi bahkan sampai berujung di Mahkamah Konstitusi. ${ }^{7}$

Tabayun konstitusi yang diwakili oleh koalisi masyarakat zakat Indonesia (KOMAZ) salah satunya yang fundamental adalah terkait dengan sentralisasi. Pasal 6 undang-undang nomor 23 tahun 2011 menyatakan bahwa Baznas merupakan lembaga yang memiliki kewenangan dalam mengelola zakat di Indonesia. Sementara LAZ yang sudah lama ada dalam pengelolaan zakat, hanya sebagai pembantu Baznas. ${ }^{8}$ Peralihan pengelolaan zakat dari desentralisasi kepada sentralisasi memang belum mencapai perubahan yang signifikan. Sebagaimana penelitian yang dilakukan oleh Nurul Huda terkait potensi zakat yang belum tergali dengan maksimal akibat prilaku muzaki yang masih tidak percaya pada lembaga dalam mengelola zakat.

Berdasarkan pemikiran diatas, tujuan penelitian untuk menganalisis undangundang nomor 23 tahun 2011 dalam mengelola zakat guna mencapai keadilan sosial dengan melaksanakan program inovasi pemberdayaan zakat yang dilasksanakan oleh Lembaga Amil Zakat dan Badan Amil Zakat Nasional.

\section{Metode Penelitian}

Pendekatan kualitatif, dengan metode penelitian deskriptif dilakukan untuk mengungkapkan dan menganalisis kejadian atau fakta pemberdayaan dana zakat di setiap lembaga yang berwenang menurut undang-undang yaitu LAZ dan Baznas. Sumber data sekunder yaitu berbagai literatur seperti buku, jurnal, dan bahan lainnya yang berhubungan dengan penelitian ini digunakan dalam melengkapi permasalahan yang ada. Sedangkan untuk menganalisisnya menggunakan pendekatan al-Maqashid alSyari'ah.

\section{Hasil Penelitian dan Pembahasan}

Zakat secara bahasa adalah tumbuh, suci, dan berkembang ${ }^{9}$. Zakat merupakan pemasukan kas Negara yang pernah dicontohkan oleh Rosulullah saw. Bahkan zakat terus lestari sebagai sumber pendapatan Negara hingga masa keemasan Islam ${ }^{10}$. Seperti tokoh ekonomi Islam Abu Yusuf seorang murid dari Abu Hanifah yang lahir pada masa keemasan Islam. Ia menulis sebuah karya dimana didalamnya membahas tentang zakat sebagai pendapatan Negara. Wilayah Islam yang sudah luas sampai mampu mengumpulkan pendapatan Negara hingga 530.312.000 dirham ${ }^{11}$.

\footnotetext{
${ }^{7}$ Yusuf Wibisono, Mengelola Zakat Indonesia (Jakarta: Prenadamedia Group, 2015), hlm. 163.

${ }^{8}$ Mufidah, "Sistem Hirarki Kelembagaan Badan Pengelolaan Zakat di Indonesia," Jurnal Cita Hukum 4, no. No. 2 (2016).

${ }^{9}$ Asmani, Zakat Solusi Mengatasi Kemiskinan Umat, hlm. 5 .

${ }^{10}$ A hmad Sarbini, "Zakat dan Pajak," Jurnal Syari'ah 2, no. No. 2 (2013): 2.

${ }^{11}$ Janwari Yadi, Pemikiran Ekonomi Islam (Bandung: Rosdakarya, 2016), hlm. 120.
} 
Penyaluran zakat telah ditetapkan oleh syari'ah yaitu tidak boleh lepas dari delapan asnaf ${ }^{12}$. Pada posisi pertama dan kedua zakat diperuntukkan bagi orang-orang yang fakir dan miskin. Artinya zakat bukan hanya rukun Islam dan ibadah langsung kepada Allah swt. Namun zakat juga mempunyai dimensi sosial ${ }^{13}$. Perintah berzakat yang beriringan dengan perintah shalat didalam Al-Qur'an ada 82 ayat. Shalat untuk mencetak kesolehan spiritual sementara zakat untuk mewujudkan kesalehan sosial. ${ }^{14}$

Zakat yang merupakan mekanisme distribusi harta kekayaan agar tidak tercipta kesenjangan di masyarakat tentu yang menjadi objeknya adalah harta kekayaan. Fakta sosial ekonomi yang berbeda mengakibatkan perubahan objek zakat dengan menambah objek zakat. Undang-undang nomor 23 tahun 2011 pasal 4 menyatakan objek zakat menurut undang-undang tersebut adalah zakat mal dan zakat fitrah yang terdiri dari perak, emas, dan logam mulia lainnya, surat berharga, uang, pertanian, perniagaan, kehutanan, perkebunan, peternakan, pertambangan, perikanan, perindustrian, rikaz, pendapatan dan jasa. ${ }^{15}$ Bahkan bukan hanya objek zakat, keadaan yang terus berubah menjadikan badan hukum sebagai subjek zakat. ${ }^{16}$

Objek zakat yang banyak membutuhkan pengelolaan yang tepat supaya tujuan zakat dalam memberantas kemiskinan terwujud. Oleh karena itu dalam menyalurkan dana zakat kini tidak lagi bersifat konsumtif tetapi lebih kearah yang produktif ${ }^{17}$. Dengan zakat yang disalurkan secara produktif maka mustahik akan mempunyai penghasilan yang terus menerus untuk memenuhi kebutuhan hidupnya dan diharapkan akan muncul muzaki yang baru.

Pendistribusian dana zakat secara produktif bisa berupa barang-barang seperti kerbau, sapi, kambing, mesin jahit, alat cukur, becak dan sebagainya sehingga mustahik bisa mengembangkan usahanya. Selain itu inovasi produk pendistribusian zakat bisa dalam bentuk bantuan dana kepada pelajar (beasiswa) atau peralatan sekolah lainnya sehingga pelajar fokus dalam mencari ilmu guna sebagai investasi generasi masa depan. $^{18}$ Dengan program penyaluran dana zakat yang telah dilakukan oleh BAZ dan LAZ secara produktif di Bogor, sebagaimana penelitian yang dilakukan oleh Nurul Huda menyatakan bahwa zakat yang disalurkan dapat mengurangi angka kemiskinan ${ }^{19}$. Di samping itu, organisasi masyarakat Muhammadiyah telah menyalurkan zakatnya secara produktif. ${ }^{20}$

${ }^{12}$ At-Taubah ayat 60

${ }^{13}$ Ahmad Syafiq, "Zakat Ibadah Sosial untuk Meningkatkan Ketaqwaan dan Kesejahteraan Sosial," ZISWAF 2, no. No. 2 (2015): hlm. 5.

${ }^{14}$ Syafiq, hlm. 6.

${ }^{15}$ Syafiq, hlm. 6.

${ }^{16}$ Imam Mustofa, "Pelaksanaan Zakat Badan Hukum," Akademika 20, no. No. 2 (2015): hlm. 6.

${ }^{17}$ Asmani, Zakat Solusi Mengatasi Kemiskinan Umat, hlm. 17.

${ }^{18}$ Adnan Abu Bakar, "Pemberdayaan Zakat untuk Pendidikan," Nur el Islam 2, no. 2 (2015): hlm. 8.

${ }^{19}$ Nurul, Zakat Perspektif Mikro-Makro Pendekatan Riset, hlm. 105.

${ }^{20}$ Neneng Hasanah, "Kontekstualitas Ayat-Ayat Hukum Wakaf Di Indonesia," Asy-Syariah Vol. 20, no. Edisi 2, (2018): hlm. 141, https://doi.org/o.15575/as.v20i2.3446. 
Atas dasar konstitusi dimana adanya hak untuk menjalankan agamanya maka Negara harus hadir dalam memfasilitasi agar dalam menjalankan ajaran agama tidak sulit dan terasa aman. Selain itu, potensi zakat yang sangat besar sebagai jaminan sosial, tentu akan membantu Negara dalam menciptakan masyarakat yang sejahtera yang berbasis pada keadilan sosial. Akhirnya formalisasi pengelolaan zakat kedalam hukum positif diawali dengan munculnya undang-undang nomor 38 tahun 1999 pasca runtuhnya Rezim Soeharto. ${ }^{21}$

Tetapi adanya kelemahan undang-undang nomor 38 tahun 1999 komisi VIII DPR RI melakukan pembahasan terkait RUU pengelolaan zakat dengan pemerintah dalam hal ini Menteri Keuangan, Menteri Agama, Menteri hukum dan hak asasi manusia, Menteri dalam Negeri. Dalam rapat fraksi, Nany Sulistyani dari fraksi partai demokrat berpendapat agar pengelolaan zakat dilakukan secara professional agar dana zakat tepat sasaran dan disalurkan dalam bentuk dana produktif bukan hanya sekedar santunan yang sifatnya sementara. Senada dengan itu Zulkarnaen Jabar dari Fraksi partai Golkar juga menginginkan agar dana zakat dikelola secara professional oleh Negara agar dana zakat bisa dikelola sesuai dengan fungsinya sebagai jaminan sosial, pemerataan ekonomi, dan pembangunan ekonomi. ${ }^{22}$

Pengelolaan dana zakat yang baik dengan adanya pengawasan tentunya harus melimpahkan kewenangan itu kepada satu badan. Lahirnya Undang-undang nomor 23 tahun 2011 pasal 7 menjelaskan lembaga yang berwenang mengelola dana zakat adalah BAZNAS sedangkan lembaga amil zakat lain diharuskan memberikan laporan kepada BAZNAS yang bertanggungjawab kepada Menteri Agama. Undang-undang tersebut merupakan perubahan menuju pada kesempurnaan dalam regulasi zakat.

Bentuk tanggungjawab Negara dalam rangka memfasilitasi hak beragama rakyatnya dan merupakan tanggungjawab sosial bagi kejahterahaan seluruh rakyat Indonesia yaitu dengan melakukan sentralisasi pengelolaan zakat. Berdasarkan terori Receptie in Complexu ada tiga unsur terkait hukum Islam di Indonesia yaitu: ${ }^{23}$ (1) Hukum Islam dapat berlaku di Indonesia bagi pemeluknya. (2) Umat Islam harus taat pada agamanya. (3) Hukum Islam berlaku universal.

Teori diatas zakat yang merupakan ajaran agama Islam dan hukumnya wajib harus diltaati oleh penganutnya. Zakat sebagaimana dalam surat Ali-Imran ayat 103 membutuhkan pengelola yang diangkat oleh Negara sebab Rosulullah saw mengangkat sahabatnya untuk mengumpulkan zakat di berbagai daerah. Jadi wajib hukumnya Negara campur tangan dalam pengelolaan zakat. Sejarah peradaban Islam pun merupakan bukti historis bahwa pengelolaan zakat dilakukan oleh Negara.

\footnotetext{
${ }^{21}$ Wawan Hermawan, "Politik Hukum Zakat di Indonesia. Jurnal Pendidikan Agama Islam. vol. 11 no. 2. 2013," Jurnal Pendidikan Agama Islam 11, no. No. 2 (2013): hlm. 6.

22 Muhammad Aziz, "Regulasi Zakat di Indonesia Upaya Menuju Pengelolaan Zakat yang Profesional," Tafaquh 3, no. 1 (2015): hlm. 9.

${ }^{23}$ Juhaya S Praja, Teori Hukum dan Aplikasinya (Bandung: Pustaka Setia, 2014), hlm. 81.
} 


\section{Program Pemberdayaan Dana Zakat di LAZ}

Praktek zakat sudah lama ada di Indonesia, namun meski demikian penyerahan dana zakat yang langsung kepada mustahik oleh muzaki sendiri dipandang tidak profesional sehingga tujuan zakat dalam dimensi sosial tidak terlihat. ${ }^{24}$ Kemiskinan di Indonesia pada maret 2015 sekitar 28, 59 juta sementara pada maret 2017 turun hingga kini mencapai 26, 58 juta jiwa. Meski turun jumlahnya namun Indonesia yang mayoritas muslim dan sumber daya alam yang melimpah angka kemiskinan bisa semakin kecil. Disamping itu dalam ideologi pancasila Negara mempunyai kewajiban untuk mewujudkan kejahteraan dan keadilan masyarakat Indonesia. Di dalam konstitusinya warga Negara Indonesia berhak atas jaminan sosial, hidup sejahtera lahir dan batin ${ }^{25}$. Upaya Negara untuk mewujudkan hal itu diterjemahkan dan dijelaskan dalam undang undangundang. Perbedaan kegiatan ekonomi dan potensi ekonomi dengan zaman Nabi menjadikan pertimbangan atas adanya pertambahan objek zakat didalam pasal 4 undangundang nomor 23 tahun 2011. Bukan hanya dari sisi penghimpunan dana zakat, agar zakat menjadi solusi dalam menyelesaikan masalah kemiskinan dan ketimpangan pasal 27 undang-undang nomor 23 tahun 2011 tentang pemberdayaan dana zakat secara produktif.

Penyaluran dana zakat kepada mustahik dengan cara memberikan dana tersebut dalam bentuk benda atau lainnya yang berakibat adanya penghasilan terus menerus untuk mustahik sehingga mustahik lambat laun akan menjadi muzaki merupakan zakat produktif. Hal ini pun pernah digagas oleh Kyai Sahal Mahfud dengan menyalurkan dana zakat kepada mustahik kemudian dana tersebut diambil dan disimpan di koperasi untuk dijadikan modal kerja sehingga mustahik mempunyai pekerjaan yang akan menghasilkan keuntungan secara berkelanjutan. ${ }^{26}$

Upaya pemerintah tidak berhenti sampai disana. Pemberdayaan dana zakat secara produktif membutuhkan perencanaan yang matang, kontrol, dan adanya evaluasi ${ }^{27}$. Untuk mewujudkan hal itu lahirnya undang-undang nomor 23 tahun 2011 dengan Negara sebagai sentralisasi yang bertanggungjawab dalam menangani kemiskinan. Sedangkan posisi masyarakat juga harus berpartisipasi dalam mewujudkan kesejahteraan dan keadilan sosial dengan jalan zakat dilindungi oleh hukum. Pasal 17 undang-undang nomor 23 tahun 2011 menyatakan bahwa masyarakat bisa membuat lembaga amil zakat.

BAZNAS merupakan lembaga pengelola zakat yang dibentuk oleh pemerintah berdasarkan undang-undang nomor 23 tahun 2011 pasal 6. Selain itu, pembentukan BAZNAS juga didasari Keputusan Presiden RI No. 8 Tahun 2001 yang bertugas dan ber-

\footnotetext{
${ }^{24}$ Asmani, Zakat Solusi Mengatasi Kemiskinan Umat, hlm. 2.

${ }^{25}$ Pasal 28 H ayat 1, 2, dan 3 UUD 1945

${ }^{26}$ Asmani, Zakat Solusi Mengatasi Kemiskinan Umat, hlm. 58.

${ }^{27}$ Ahmad Tabik, "Manajemen pengelolaan zakat yang Efektif di Era Kontemporer.," ZISWAF 2, no.
} No. 2 (2015): hlm. 13. 
fungsi dalam mengumpulkan dan mendistribusikan zakat, infaq, dan sedekah (ZIS) secara nasional. Selanjutnya, BAZNAS mempunyai program yang bernama rumah sehat dengan visi menjadi model pelayanan dan pemberdayaan kesehatan khususnya masyarakat dhuafa yang berstandar nasional. Rumah sehat BAZNAS merupakan pelayanan kesehatan untuk mustahik atau untuk di daerah yang terkena bencana. Jenisnya adalah dengan konsep pelayanan di dalam ruangan dan di luar ruangan. Model pelayanan dalam ruangan seperti adanya dokter umum, UGD, dokter spesialis, konsultasi psikologi, unit farmasi, ambulance, ruang rawat inap, dan khitanan masal. Sedangkan pelayanan di luar ruangan seperti pemberian edukasi kesehatan kepada masyarakat dan pengobatan untuk kaum dhuafa. ${ }^{28}$

Program lainnya dalam pendayagunaan zakat yang dikeluarkan oleh BAZNAS adalah Microfinance. Microfinance adalah suatu lembaga yang membantu dalam pembiayaan produktif kepada orang yang berhak (mustahik) berdasarkan prinsip non for profit dengan maksud melakukan pengembangan wirausaha. Modal yang yang diberikan oleh lembaga microfinance dalam pengembangan wirausaha merupakan faktor yang sangat penting. Jika hanya mengandalkan dari modal mustahik tentu kecil dan usaha akan lambat berjalannya. Sebaliknya jika permodalan ditopang oleh perbankan tentu akan sulit karena dalam administrasinya akan menemui kendala. Oleh karena itu demi meningkatkan perekonomian lebih jauhnya keadilan sosial, akses untuk mendapatkan pendapatan dipermudah dengan adanya program dari BAZNAS. Adapun agar mendapatkan bantuan maka mustahik harus mempunyai rekening bank dan surat keterangan usaha minimal dari kelurahan serta usahanya sudah ada kurang lebih selama satu tahun. ${ }^{29}$

Salah satu lembaga amil zakat hasil pembentukan masyarakat yaitu Dompet Dhuafa, Yayasan ini berdiri pada tahun 1994 dan dikukuhkan pada tahun 2001 sebagai lembaga amil zakat dengan beberapa program pemberdayaan zakat. Pemberdayaan dana zakat tidak lagi bersifat konsumtif namun lebih produktif. Seperti program pemberdayaan dana zakat divisi ekonomi. Tujuannya adalah supaya tercipta lahan pekerjaan baru sehingga angka kemiskinan berkurang. Dompet Dhuafa Jawa Barat meluncurkan program pendaki (pendampingan pedagang keliling). Program ini merupakan pemberdayaan dana zakat yang diberikan kepada para pedagang kaki lima dengan bantuan grobak agar grobak tersebut menarik dan higienis serta menjadikan sumber pendapatan. Untuk fasilitas pendaki ini tentu melalui seleksi atas pendapatan pedagang dan keadaan grobak $^{30}$.

\footnotetext{
${ }^{28}$ baznas.go.id/rsb (diakses pada tanggal o8-11-2018 pkl. 21.15 WIB)

${ }^{29}$ baznas.go.id/bmf (diakses pada tanggal 08-11-2018 pkl. 21.20 WIB)

${ }^{30}$ dompetdhuafa.org/ekonomi/profil (diakses pada tanggal 08-11-2018 pkl. 21.40 WIB)
} 


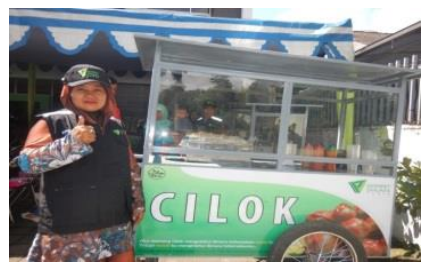

Gambar: 1 Penyaluran Grobak dalam Program Pendaki dari Dompet dhuafa

Lembaga Amil Zakat lain seperti Dompet Peduli Umat Daarut Tauhid yang bertindak sebagai lembaga amil zakat nasional (LAZNAS) berdasarkan SK Menteri Agama no. 410, mempunyai program pemberdayaan dana zakat infak dan sedekah. Program Beasiswaku adalah program pemberdayaan dana ZIS untuk fakir miskin yang mempunyai potensi dalam pendidikan namun terbentur dengan biaya pendidikan. Program Beasiswaku hadir dari mulai tingkat TK/PAUD, SD, SMP, SMA, dan Perguruan tinggi. ${ }^{31}$

Untuk bisa mendapatkan dana zakat dalam bentuk beasiswa di DT peduli maka harus memenuhi kriteria dan administrasi dibawah ini: 1) Beragama Islam, 2) Masih aktif kuliah, 3) Tidak merokok, 4) Mahasiswa semester 2-6 (jenjang pendidikan D3/S1) (Tidak Sedang (uti), 5) IPK Minimal 3, 0,6) Wajib tinggal di Asrama (Ikhwan), 6) Belum menikah, 7) Tidak pacaran, 8) Bersedia aktif fi lembaga DT Peduli, 9) Siap diasramakan *bagi cabang yang mengadakan program asrama.

Persyaratan Administrasi: 1) Pas foto berwarna ukuran 4x6 (2 buah), 2) Foto kopi kartu keluarga, 3) Foto kopi KTM/KTP, 4) Foto kopi transkrip nilai keseluruhan, 5) Surat Keterangan Tidak Mampu (SKTM), 6) Surat keterangan dari kampus tidak mendapat beasiswa dari lembaga lain, 7) Surat keterangan sanggup aktif dalam program DT Peduli, 8) Surat keterangan aktif dalam organisasi, dan 9) Sertifikat prestasi

Sedangkan Misykat Secara administrasi masyarakat menyerahkan KK, KTP, dan surat keterangan tidak mampu (KTM). Mustahik yang menjadi sasaran misykat bukanlah golongan fakir namun golongan miskin yang mempunyai pendapatan dibawah UMK dan memiliki potensi bangkit dalam usahanya sehingga dana zakat tidak digunakan secara konsumtif tetapi produktif. ${ }^{32}$ Sasarannya selain sebagai mustahik juga merupakan wanita karena wanita memiliki disiplin dan komitmen yang tinggi serta wanita banyak terjerat pada riba. Setiap orang pada mulanya mendapatkan sekitar Rp. 500.000 dengan menggunakan akad qordul hasan. Ketika usahanya terlihat berkembang ada penambahan modal usaha sekitar Rp. 1000.000 dengan akad bagi hasil (mudharabah). Dana tersebut dikembalikan kepada misykat dalam jangka waktu 40 minggu yang pada akhirnya akan menjadi milik mustahik. ${ }^{33}$

\footnotetext{
${ }^{31} \mathrm{dpu}$-daaruttauhiid.org/web/program/3 (diakses pada tanggal 08-11-2018 pkl. 22.00 WIB)

${ }^{32}$ Wawancara dengan Riyadi (Menejer Penelitian dan Pengembangan Program DT Peduli), Bandung, 13 Desember 2018.

33 Wawancara dengan Iwan Setiawan (Ketua Koperasi Misykat dt Peduli), Bandung, 13 Desember 2018.
} 


\section{Inovasi Pemberdayaan dana Zakat dalam Al-Maqâshid Al-Syarî’ah}

Penyaluran zakat secara konsumtif tidak berhasil mengurangi angka kemiskinan secara signifikan. Sebaliknya penyaluran dana zakat secafa produktif mampu mengurangi angka kemiskinan. Esensi zakat adalah supaya harta tidak terkumpul hanya pada orang kaya saja tetapi harta tersebut berputar di masyarakat sehingga masyarakat yang miskin merasakannya. Allah swt berfirman:

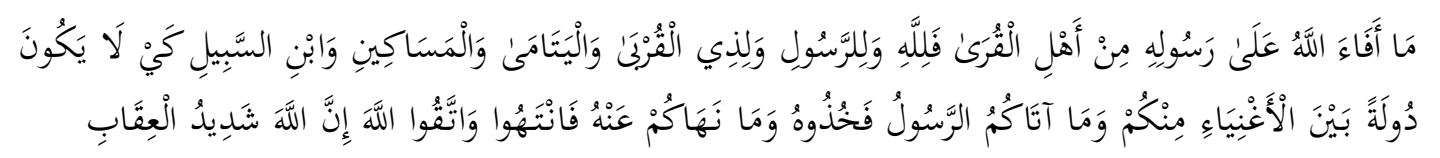

harta rampasan apa saja (fai-i) yang diberikan Allah untuk Rasul-Nya (dari harta benda) yang didapatkan dari penduduk kota-kota maka adalah untuk Allah, Rasul, kaum kerabat, anak-anak yatim, orang-orang miskin dan orang-orang yang dalam perjalanan, supaya harta itu tidak beredar di antara orang-orang kaya saja di antara kamu. Apa yang menjadi pemberian Rasul untukmu, maka terimalah. Dan apa saja yang menjadi larangan bagimu, maka tinggalkanlah. Dan bertakwalah kamu sekalian kepada Allah. Sesungguhnya Allah itu sangat keras hukumannya. (Al-Hasyr: 7).

Potensi zakat yang sangat besar hingga mencapai 217 triliyun dan tingginya angka kemiskinan di Indonesia menuntut pengelolaan zakat dari konsumtif tradisional menuju pada pengelolaan produktif kreatif dengan dikelola secara professional. Dengan demikian tujuan zakat dalam pengentasan kemiskinan tercipta dan keadilan sosial bagi seluruh rakyat bukanlah hal yang utopis. Penyaluran zakat secara produktif dapat dilakukan dalam bentuk barang-barang atau program-program seperti beasiswa, alat-alat sekolah, alat-alat produksi, permodalan dan rumah sakit atau sarana kepentingan umum. ${ }^{34}$

Terkait dengan penyaluran dana zakat untuk maslahah umum Imam Ahmad bin Hanbal sebagaimana dikutip oleh Jamal Ma'mur Ashmani mengatakan bahwa maslahah umum termasuk pada sabilillah ${ }^{35}$. Sedangkan penyaluran dana zakat dalam bentuk permodalan dan alat-alat produksi seperti mesin jahit, becak, dan traktor pernah digagas oleh Kyai Sahal dengan merujuk pada kitab Anwarul Masalik karya Syeikh Muhammad Zuhri al-Ghamrawi halaman $115^{36}$. Jika kita menelaah pelaksanaan pendayagunaan zakat pada masa Nabi Muhammad SAW hingga masa Khulafaur Rasyidun, zakat difungsikan sebagai alat dalam menciptakan mayarakat Islam yang sejahtera dan makmur. Kondisi ini, dilanjutkan hingga masa Tabiin dimana kemaslahatan ummat Islam benar-benar diperhatikan ${ }^{37}$. Kemaslahatan merupakan prinsip dalam hukum Islam. Maslahat terbagi menjadi tiga yaitu maslahat mu'tabaroh (dharuriyyah, hajiyyah, dan tahsiniyyah), maslahat mulghah, dan maslahat mursalah. Maslahat juga merupakan tujuan dari syari'ah.

\footnotetext{
${ }^{34}$ Kutbuddin Aibak, "Zakat dalam Perspektif Maqashidal-Syari'ah," Ahkam 3, no. 2 (2015): hlm. 11.

${ }^{35}$ Asmani, Zakat Solusi Mengatasi Kemiskinan Umat, hlm. 9.

${ }^{36}$ Asmani, hlm. 20.

${ }^{37}$ Aibak, "Zakat dalam Perspektif Maqashid al-Syari'ah," hlm. 3.
} 
Hukum-hukum yang ada dalam Al-Qur'an dan Hadits ditujukan pada terciptanya penjagaan atas agama, jiwa, akal, keturunan, dan harta. ${ }^{38}$

Berdasarkan uraian singkat tentang zakat di atas, tujuan dari pengelolaan zakat adalah menciptakan masyarakat yang sejahtera, makmur dan mashlahah. Oleh sebab itu, pengelola zakat baik secara formal maupun informal perlu ditegakkan demi terciptanya tujuan tersebut. Pengelolaan zakat mal (harta benda) maupun zakat ftrah (jiwa) yang maksimal berpotensi mengurangi angka kemiskinan yang terjadi pada masyarakat di Indonesia. Namun, faktanya Indonesia dalam pengelolaan zakat masih belum optimal sehingga tujuan kemahslahatan ummat belum terlaksana.

Penekanan pelaksanaan maqashid al-syariah yang diprakarsai oleh Al-Syathibi secara umum bersumber dari kandungan ayat suci Al-Qur'an menjelaskan hukum yang diciptakan bermanfaat demi kemashlahatan ummat. Karenanya, pelaksanaan pengelolaan zakat produktif perlu dilakukan dengan mengamalkan maqashid al-syariah dalam kebijakan demi terwujudnya kemaslahatan umat, kesejahteraan dan kemakmuran masyarakat.

Program penyaluran dana zakat dalam bentuk modal usaha berupa uang atau pun barang seperti gerobak merupakan inovasi produk yang didasarkan pada kemaslahatan sehingga tujuan zakat tercapai yaitu harta kekayaan tidak hanya berputar pada orang kaya saja. Penyaluran dana zakat dalam bentuk fasilitas kesehatan juga merupakan kemaslahatan karena bidikannya tetap orang-orang yang tidak mampu (mustahik) sehingga mustahik tidak mengeluarkan biaya untuk berobat ketika sakit. Kesehatan mustahik yang penting terlebih jika ia merupakan tulang punggung keluarga. Berbeda jika penyalurannya hanya diberikan dalam bentuk uang secara langsung, tentu kemungkinan untuk dikonsumsi seluruhnya besar sehingga apabila ia sakit memerlukan biaya tambahan yang bisa jadi itu semakin memberatkan mustahik. Dengan adanya inovasi produk dana zakat, dana zakat di atur demi menolong para mustahik. Sama halnya dengan penyaluran dana zakat dalam beasiswa. Pendidikan merupakan hak dasar dari setiap orang. Dengan pendidikan masa depan seseorang akan lebih baik. Mustahik yang tidak mempunyai akses kesana menjadi bisa tetap berpendidikan dengan adanya kemasan produk penyaluran dana zakat dalam bentuk beasiswa.

\section{Kesimpulan}

Zakat merupakan sistem fiskal Islam yang berbeda dengan kebijakan fiskal sistem ekonomi lain. Zakat mempunyai tujuan dalam kesejahteraan manusia. Perbedaan potensi manusia sehingga melahirkan kaya dan miskin kerap kali menjadi benih konflik. Islam hadir dengan melegitimasi pengambilan harta yang berada pada seseorang dengan ketentuan-ketentuan yang telah ditentukan. Potensi zakat yang besar namun angka kemiskinan yang masih tinggi merupakan permasalahan. Zakat yang pernah berhasil

\footnotetext{
${ }^{38}$ Jaih Mubarok, Sejarah dan Perkembangan Hukum Islam (Bandung: Rosdakarya, 2003), hlm. 8.
} 
dengan gemilang dalam menciptakan kemaslahatan pada masa Islam Klasik seharusnya menjadi referensi untuk pengelolaan zakat kontemporer.

Pemberdayaan zakat secara konsumtif tidak memberikan dampak signifikan dalam mengurangi angka kemiskinan. Oleh karena itu pemerintah yang mempunyai tanggungjawab dalam hal itu pada setiap kebijakannya harus memperhatikan kemaslahatan umum. Hal itu telah dilakukan dengan lahirnya undang-undang nomor 23 tahun 2011. Meski didalamnya masih ada kekurangan namun undang-undang itu melegitimasi pengelolaan zakat secara produktif. Sistem ekonomi Islam melalui zakat merupakan solusi untuk menanggulangi kesenjangan sosial yang akan berakibat pada kecemburuan sosial, konflik sosial, bahkan sampai revolusi sosial. Dengan pengelolaan zakat yang baik sehingga mustahik mampu mengembangkan dana zakat yang diterima guna meningkatkan taraf kehidupannya.

Undang-undang nomor 23 tahun 2011 merupakan bukti nyata pemerintah dalam tanggungjawabnya untuk menciptakan kesejahteraan meski dinilai belum sempurna. Sentralisasi dalam undang-undang nomor 23 tahun 2011 adalah implementasi ajaran Islam dalam pengelolaan zakat. Oleh karena itu undang-undang tersebut merupakan penyempurna dari undang-undang sebelumnya dan terkandung didalamnya tujuantujuan syariat.

\section{DAFTAR PUSTAKA}

Abu Bakar, Adnan. "Pemberdayaan Zakat untuk Pendidikan." Nur el Islam 2, no. 2 (2015). Aibak, Kutbuddin. "Zakat dalam Perspektif Maqashid al-Syari'ah." Ahkam 3, no. 2 (2015). Anonim. Uang Kertas vs Dinar dan Dirham Islam. Bogor: Pustaka Izzah, 2011.

Asmani, Jamal Ma'mur. Zakat Solusi Mengatasi Kemiskinan Umat. Yogyakarta: Aswaja, 2016.

Aziz, Muhammad. "Regulasi Zakat di Indonesia Upaya Menuju Pengelolaan Zakat yang Profesional." Tafaquh 3, no. 1 (2015).

Hakim, Rahmat. Hukum Pidana Islam. Bandung: Pustaka Setia, 2010.

Hasanah, Neneng. "Kontekstualitas Ayat-Ayat Hukum Wakaf Di Indonesia." Asy-Syariah Vol. 20, no. Edisi 2, (2018): hlm. 141. https://doi.org/o.15575/as.v2oi2.3446.

Hermawan, Wawan. "Politik Hukum Zakat di Indonesia. Jurnal Pendidikan Agama Islam. vol. 11 no. 2. 2013." Jurnal Pendidikan Agama Islam 11, no. No. 2 (2013).

Mubarok, Jaih. Sejarah dan Perkembangan Hukum Islam. Bandung: Rosdakarya, 2003. Mufidah. "Sistem Hirarki Kelembagaan Badan Pengelolaan Zakat di Indonesia." Jurnal Cita Hukum 4, no. No. 2 (2016).

Mustofa, Imam. "Pelaksanaan Zakat Badan Hukum." Akademika 20, no. No. 2 (2015).

Nurul, Huda, dan dkk. Zakat Perspektif Mikro-Makro Pendekatan Riset. Jakarta: Prenadamedia Group, 2015.

Praja, Juhaya S. Teori Hukum dan Aplikasinya. Bandung: Pustaka Setia, 2014. 
Sarbini, Ahmad. "Zakat dan Pajak." Jurnal Syari'ah 2, no. No. 2 (2013).

Syafiq, Ahmad. "Zakat Ibadah Sosial untuk Meningkatkan Ketaqwaan dan Kesejahteraan Sosial." ZISWAF 2, no. No. 2 (2015).

Tabik, Ahmad. "Manajemen pengelolaan zakat yang Efektif di Era Kontemporer." ZISWAF 2, no. No. 2 (2015).

Wibisono, Yusuf. Mengelola Zakat Indonesia. Jakarta: Prenadamedia Group, 2015.

Yadi, Janwari. Pemikiran Ekonomi Islam. Bandung: Rosdakarya, 2016.

Undang-undang nomor 23 tahun 2011 tentang pengelolaan zakat.

Undang-Undang Dasar RI 1945. 
68 | Asy-Syari'ah Vol. 21 No. 1, Juli 2019 
Asy-Syari'ah (P-ISSN : 2086-9029 E-ISSN: 2654-5675) is a periodical scientific journal that publishes various results of studies and research, literature review, and other scientific works whose scope covers the field of Islamic law/sharia, law and society in monodisciplinary, interdisciplinary, and multidisciplinary manners. The journal aims to expand and create innovative concepts, theories, paradigms, perspectives and methodologies in the above said scope. The Journal is published twice a year (june and december) by Faculty of Shariah and Law, Sunan Gunung Djati State Islamic University Bandung in collaboration with Asosiasi Sarjana Syariah Indonesia (ASSYI).

\section{EDITORIAL OFFICE:}

Fakultas Syariah dan Hukum UIN Sunan Gunung Djati Bandung Jl. Raya A.H. Nasution No. 105 Cibiru Kota Bandung, 40614

Tlp/Fax: +022-7802278 Faks. 022-7802278

Website http://journal.uinsgd.ac.id/index.php/asy-syariah/index

E-mail: Jurnalasy-syariah@uinsgd.ac.id 